\title{
Motivating Bilingual Students to Study Foreign Languages: A Case Study of Learning Russian as a Foreign Language
}

\author{
Svetlana L. Savilova, ${ }^{1}$ Eugenia V. Kokhanovskaya ${ }^{1}$, Elena G. Smychkova ${ }^{1}$, Anna A. \\ Kropotkina, ${ }^{1}$ Marija Chaj ${ }^{1}$ \\ ${ }^{1}$ First Moscow State Medical University (MSMU) named after I.M. Sechenov (Sechenov University), \\ Moscow, the Russian Federation
}

Keywords: Bilinguals; Increasing Motivation; Etymological Analysis; Russian as a Foreign Language; Derivational Nests; Information Technologies.

Abstract: The article studies the issue of increasing the motivation of bilingual students to study foreign languages, in particular Russian language. The authors analyzed modern educational technologies for teaching Russian as a foreign language (RFL) used by professors of the National Research Tomsk Polytechnic University. In this article we observed a range of methods for successful teaching of RFL, which includes the use of etymological analysis to increase the literacy and comprehension of derivational nests in the Russian language, digital educational resources (DER), interactive technologies, and students' independent work. This combination of approaches makes lessons more interesting, facilitates active learning, and promotes independence in order to substantially increase their motivation for RFL studies as well as their level of mastery. The article presents a new approach to using educational and monitoring computer software for teaching Russian to foreign students, which helps to optimize the educational process and prepare highly qualified specialists able to meet the needs of the modern society. The use of software is a key component of developing foreign students' communication, social and cultural competence, acquisition of practical skills and accumulation of factual knowledge.

\section{Introduction}

Motivation to study foreign languages is most effective when it is based on ethnic and cultural characteristics and local teaching traditions. This is reflected in a number of articles of foreign researchers. Many foreign researchers have studied the issue of motivation in practical settings, find out and consider types of motivation $[1 ; 6 ; 7 ; 13 ; 19 ; 18]$ and second language (L2) learner motivational types [12]. Number of articles are dedicated to the English and Chinese due to a high demand for these language learning. This concerns not only L2 learners, but also the teaching staff $[3 ; 16]$.

A study of the motivation of Pakistani students learning English demonstrated that instrumental motivation (in which foreign language ability is perceived as a means of deriving certain social and economic benefits, such as higher salary, bonuses, acceptance into prestigious educational 
institutions, etc.) is more effective than integrative motivation consisting of a student's wish to communicate with people in the new language and learn their culture [1].

Another study of motivation of Lebanese students learning English showed, on the contrary, that integrative motivation, diligence, desired results, expectations, and assessment of one's own abilities were the determining factors in the success of learning a foreign language. Instrumental motivation is just an addition to integrative motivation [7].

Investigating the Chinese students' motivation to learn English, the Canadian researcher, Naghmeh Babaee, made a survey of the relevant literature [13]. One of the problems he identified in his survey was as follows: many Chinese learners of English might not have the opportunity to use it beyond classrooms. So, the teachers need to inspire them in different ways. This literature review highlights the need for teachers to praise their students for their own accomplishments, instead of comparing them with their peers. It helps to increase the students' motivation and reduce stress [13]. The author also lists other means of increasing the students' motivation, such as: the introduction of an entertainment component in the curriculum, an engaging personality of the teacher, and an attractive design of textbooks and teaching materials. Motivation can be also effective when it is based on cultural materials: games, songs, and stories that excite students to learn a foreign language and increase their academic progress.

The study of motivational factors of US students learning Chinese language demonstrated that the interest in Chinese culture is a primary motivation for the students [19].

In Great Britain, teaching and learning Chinese as a foreign language also involves a number of approaches based on culture. Elements of culture and cultural interaction are actively used in teaching a foreign language [18]. To develop, monitor and study the effectiveness of this approach it is important to keep track of the students' goals, expectations, and skills in cross-cultural communications; to develop teaching aids; provide training to teachers; survey the students; and conduct open lessons. These methods will help assess how efficiently the students are mastering a new culture and acquiring intercultural communication skills through their study of a foreign language [18].

Modern society places heavy demands on high university degree specialists. It has become quite clear that for a graduate's successful self-realization it is not enough to just complete the course, but it is important to develop the knowledge and skills necessary for continued self-education, finding creative solutions to professional problems, and self-improvement. We believe that the most important goal of teaching in a modern higher school is to help the students acquire general and professional competencies, and to develop their skills and abilities to solve various problems in their future professional activities.

One of the key challenges in higher education pedagogy is increasing the effectiveness of each class [14].

Motivation has been widely accepted by both teachers and researchers as one of the key factors influencing the rate and success of second / foreign language (L2) learning. Without sufficient motivation, even individuals with most remarkable abilities cannot accomplish long-term goals [4].

A psychologist A.N. Leontiev, who supports the idea of a connection between motive and need, believes that "the need alone cannot cause purposeful activity but is just a prerequisite, an internal condition for activity. Before it is met for the first time, the need "does not know" its object, it must first be discovered. Only upon such discovery the need acquires its object, as well as the intellectually perceived (imagined) object acquires its function of incentivizing and directing the activities, i. e. it becomes a motive" [8].

Many Russian and foreign research [4; 9] papers emphasize the significance of the teacher and his/her motivational activities. The students' level of interest and the teacher's engagement are tightly interconnected [10]. 
Teaching bilingual students involves seeking new opportunities and innovative teaching methodologies [17].

Experimental research shows that the use of etymological analysis as a training methodology helps to:

- $\quad$ expand students' vocabulary and the knowledge of individual lexical units,

- make their understanding of the meaning of Russian words more specific and motivated,

- improve their linguistic intuition and communication skills and teach them to predict a word's meaning.

Despite a significant number of studies in the field of etymology, the etymological aspect of learning vocabulary is barely represented in the RFL teaching methodology, which indicates a clash between theoretical research and the practice of RFL teaching. It also shows the need to develop the theoretical foundation and the didactic principles for creating a set of exercises for teaching RFL in its etymological aspect using DER (digital education resources) and organizing students' independent work. The need to overcome this identified contradiction makes our research relevant.

\section{Objectives and Methodology}

The subject of our research is the effectiveness of the methodology for teaching RFL to bilingual students using etymological commentary, DERs, and the set of exercises that has been developed.

The objective of the research is to:

a) develop the students' motivation to study;

b) develop and theoretically substantiate the comprehensive methodology using etymological commentary and DERs;

c) deepen the basic knowledge of etymology (promoting a reasoned and motivated understanding of RFL); the use of DERs, and students' independent work as support resources improves their motivation to study RFL;

d) design the exercises for using etymological analysis, which are useful for improving the knowledge of RFL as an additional resource and which increase the students' motivation to study the subject;

e) organize bilingual students' independent work in forming and developing skills to analyze lexical units within the word family system with an understanding that the history of a word helps one to understand, remember and structure the studied language's vocabulary; and

f) improve the level of linguistic knowledge and the ability to analyze lexical units.

To achieve this objective it is necessary to address the following challenges in linguistic methodology:

1. developing the scientific framework for teaching bilingual students RFL using etymological commentary, DERs, and independent student work;

2. determining, using specially developed tests (based on etymological analysis), the students' level of linguistic proficiency, and assessing the student's level of motivation to study RFL using DERs;

3. developing a set of teaching exercises for bilingual students to improve their motivation to study the subject.

In this research the following methods were used:

- analysis of the relevant linguistic methodological literature;

- surveying the students to determine the ways to improve their motivation to study RFL using etymological analysis, DERs, etc.;

- setting up and conducting a teaching experiment (to ascertain, teach and assess); 
- analysis of experimental data obtained to verify the effectiveness of developed methodology to improve the students' motivation to study RFL.

\section{Results and Discussion}

We assume that one of the main ways to increase the students' motivation and the effectiveness of RFL classes is the synthesis of modern technologies and active learning techniques with traditional teaching models. The student's educational activity is stimulated primarily by internal motivation, when his/her cognitive need "meets" the subject of the activity, developing a generalized path of action, and becomes "objectivized" in it. At the same time, it can be stimulated by various external motives: self-assertion, prestige, duty, necessity, achievement, etc.

In February 2012, a research experiment started which goal was to improve the students' motivation to study RFL. The sample for the experimental research was comprised of full-time students of the Institute of International Education and Language Communication. The students' basic Russian proficiency level and motivation for learning were practically identical in the selected groups. In addition to that, the students were of about the same age and were studying in the same professional field. The experimental research included ascertaining, teaching and assessing stages.

At the ascertaining stage, the students' motivation to study RFL was determined using Ehlers test, designed to determine the students' general motivation, their readiness to achieve success in all areas of activity. This type of diagnostic shows both the student's interest in success and his level of risk-taking (fear of failure). The stimulus material consists of 41 phrases, to which the respondent must reply with a "yes" or a "no". The test belongs to a single-scale testing methodology. The results are represented in Figures 1 and 2.

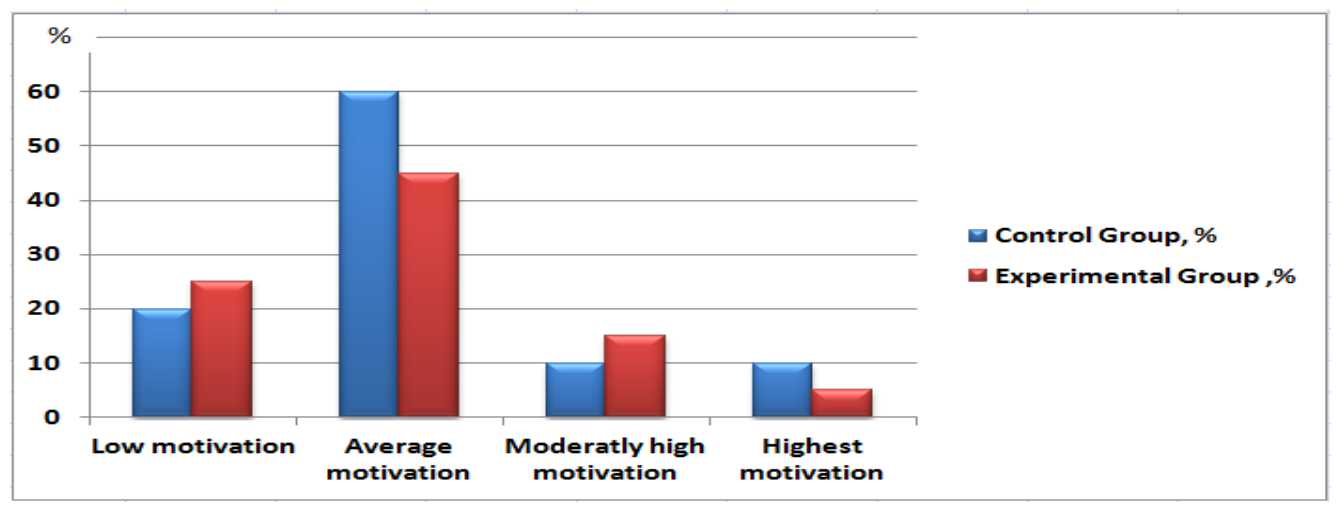

Figure 1. The Students' Motivation Level: Control and Experimental Groups in Percentages

Both examined groups exhibited an average level of motivation for success in education, but slightly higher indicators were observed in the first group. This is why we selected the group with lower motivational indicators as our experimental group. In the experimental group, $45 \%$ of the students showed average, and 15\% moderately high level of motivation for success, while in the control group $60 \%$ of the students showed average, and $10 \%$ moderately high level of motivation for success. The predominance of an average motivation level may be explained, in our opinion, by the fact that all examined students are 2nd and 3rd year students who are successfully continuing their education.

The data obtained suggests that the students who have a moderately high orientation for success prefer a medium level of risk-taking. Based on our analysis of the monitored electronic journals, these are the students who have a reliable level of knowledge and whose grades are primarily "good" and "excellent" [B and A students]. Those who are highly motivated to succeed and are 
highly prepared to take risks find themselves in uncomfortable situations less often than those who are highly prepared to take risks, but are also highly motivated to avoid failures (defensive). The higher the student's motivation to succeed, to reach a goal, the lower their readiness for risk. Their motivation to succeed also affects their hope for success: if the motivation for success is high, their hope for success is usually more modest than if their motivation for success were weak.

The main task for the formative stage of the experiment was to select the teaching methodology to improve the students' motivation to study RFL. The selected set of methodologies to improve the motivation of students learning RFL has been periodically used to teach both liberal arts and scientific subjects.

During the formative stage of the experimental research the students were divided into a control group (CG) and an experimental group (EG). In the control group, traditional teaching forms, methods and means were used. In the experimental group, RFL was taught using a set of methods combining both traditional and modern methodologies.

Over the course of teaching both CG and EG, we identified the strengths and weaknesses of this approach to teaching RFL. Advantages of this approach were manifested in student work (engagement, developing competence, team work, creativity etc.), but this methodology significantly increased the teacher's preparation time.

The goal of the control stage of the experimental research was to assess the dynamic of students' motivation to study RFL. This was done through testing and observation.

According to EG students, it was, first of all, more interesting to work; secondly, they were more actively engaged and independent in their choice of information field; thirdly, they faced fewer challenges (it was helpful to have team work and differentiated task distribution, which created a sense of success at every stage). The students noted that along with the increased level of motivation to study, they were able to improve their proficiency in Russian. The students in this group also noted that their motivation to study RFL was reduced when they have to retell texts, mechanically memorize textbook theories, and complete "template" vocabulary and grammar tests.

The motivation of CG students remained static and the students emphasized challenges in mastering the language, namely: difficulty understanding texts and idioms as well as the use of vocabulary and grammar in preparing answers. The results show that there were no significant changes in the CG: $30 \%$ of the students demonstrated an average level of motivation and $50 \%$ of the students demonstrated a moderately high level of motivation for success. In EG, $40 \%$ of the students demonstrated an average level and 50\% demonstrated moderately high motivation for success. Low and excessively high motivation was shown in only singular cases, which confirms that the testing was done correctly.

\subsection{Students' Motivation}

Researchers and practitioners [2; 11] point out the significant reduction in students' motivation as a problem that for a long time has been one of the central issues in psychology and pedagogy. We believe that motivation significantly affects a person's behavior and relationships in all spheres of life, including the educational system. Motivation, understood as the sum total of various stimuli (needs, motives, feelings, desires etc.), determines, induces, and encourages a person to carry out certain acts within the activity defined by such motivation. Having awareness of principles of forming and developing of motivation allows more successfully addressing challenges in education. Motivation is particularly important in education and a professional career, which is why the instructor needs to know and understand students' educational motives and to actively influence their development.

Motivation plays a key role in studying any subject area, especially foreign languages. Success in large measure depends on what motivates students in their learning of a foreign language. 
Motivation is a primary component of any educational structure. At the same time, the importance of the person as a subject of such education is also great. External things, subjects, ideas, feelings and experiences can be a motive, in other words, anything in which a need finds its manifestation.

There are two types of motivation: internal and external. Internal motivation evolves under the influence of the student's own thoughts and goals and results in an awareness of internal need. External motivation is determined by circumstances that force the student to memorize vocabulary, read texts or complete exercises against their will. External factors may include exams, work, conferences, internships, etc. Students have to continuously perfect their RFL knowledge, create conditions for studying, and avoid lengthy interruptions because they are not conducive to deep knowledge. Internal motivation, dominating over other motives, ensures successful learning and creates a sense of satisfaction from the process of studying, the results of one's work, and the acquired skills. Internal motives are related to the curriculum content and the mastering of RFL reading and writing skills. Based on this, one can say that despite various existing methodologies, motivation can be understood as the sum total of various systems of diverse psychological factors that determine the person's behavior and activities. In this article, we will use the term "motivation" to mean the pedagogical impact of various methods and means of teaching Russian as a foreign language to stimulate the students to successfully master the subject.

When students first start studying RFL, not one instructor can complain about their lack of interest in the subject. The excitement of the educational process and the novelty of the subject leave no student indifferent. Students who lack motivation to study RFL are unlikely to learn anything at all. The teacher's goal is to ensure that this interest is continuous and sustained. And where there is interest there is success. There are many ways to motivate students to study RFL such as: creating an atmosphere of enthusiasm, optimism and students' belief in their abilities and opportunities, students' correspondence with their Russian peers (via social media or email), meetings with native Russian speakers, etymological work, work with newspaper materials (or Internet materials), the use of new information technologies (presentations, DERs etc.), off-campus academic competitions, music, etc.

\subsection{Digital Educational Resources}

Modern situations in higher education show that teaching classes using new information technologies is necessary. It should be noted that introduction of multimedia software into the educational process does not need to exclude traditional educational methodologies, but should harmonize with them. Because of this, the need has emerged to use computer technologies in preparation for classes, and during the classes, to engage the students in interactive educational activities using multimedia resources. DERs help bilingual students take a new look at dry textbook facts. The main purpose of DERs is to help form sustained motivation through engaging the students and the instructor in the educational process. A qualitative improvement in educational results can be achieved only through the reasonable combination of accumulated methodologies, personal experience and modern technologies. The benefits of DERs are obvious: the ability to deliver differentiated and individualized teaching, interactivity, test quality, visual representation, the use of audio and video, the potential of using DERs to work with gifted students, remote participation in academic competitions, contests, and conferences.

The DERs' innovative characteristics include:

1. The support of all components of the educational process: obtaining information, hands-on training, evaluation (control over educational accomplishments).

2. Interactivity that ensures drastic expansion of opportunities for independent work through the use of engaging interactive educational formats. 
3. The opportunity to obtain a more comprehensive education outside the classroom. The emphasis on "comprehensive" is not accidental. This is not about the retrieval of texts from remote sources. In this case, comprehensive education means the ability to complete "at home" (at an Internet cafe, at a library, at a friend's home, ultimately, outside the classroom) the kinds of educational activities that in the past could only have been done at school or at the university: studying new material for a given subject, ongoing knowledge control including assessment and development, preparing a thesis, and much more, including remote educational team work. Good DER will have all of these innovative qualities thanks to the use of the new teaching tools mentioned above.

\subsection{Etymological Work}

Vocabulary and spelling work is among the most important goals in the system of teaching RFL. The students' spelling literacy directly depends upon the instructor's ability to effectively organize the classes to study new vocabulary words and phrases. Already back in the days before the Russian Revolution, when explaining the spelling of certain words that were difficult for the students, the teacher used information regarding etymology. In his day, K. Ushinsky stated that in third grade children should already know that the word "prozrachny [transparent]" is from the word zret' [to ripen, behold] etc.

Modern secondary school actively uses etymological analysis and insufficient attention is paid to this during lessons. Students are forced to learn all dictionary words without motivation, frequently without an explanation of the meaning of the words. Russian spelling, which is mainly etymological, provides rich material for this. It forces one to break words down into their component parts and to search for related forms in them. For example, there is a need for a scholarly justification regarding the rule on the spelling of vowels that have not been checked for stress. Textbook authors recommend that students mechanically remember the spelling of dictionary words, but this approach causes mnemonic difficulties for students, first of all due to the fact that there are so numerous, and secondly because rote memorization without understanding or thought is the most difficult form for obtaining knowledge. Such learning cannot be interesting. Learning actively requires a student to memorize. Psychologists talk about what an amazing memory a child has for fairytales, stories and histories. Etymological information regarding words is similar to amazing fairy tales and stories. Understanding is a necessary condition for remembering. Having understood how a dictionary word was formed using etymological analysis, foreigners can more easily remember how it is written without having to turn to memorization. The etymological analysis of words supports and develops interest towards RFL thanks to its impact on the development of the speech of students, their thinking, their imagination, their memory, and their attention. The integration of etymological materials on RFL in practical lessons will help the following:

- overcoming the fragmentary and mosaic-like knowledge of students;

- more effective learning of a sharper spelling eye during RFL lessons and the development of the creative potential of the student as a whole. Etymological analysis has a strong impact on students, that is, it creates conditions for the thoughtful remembering of words, making it possible to concentrate their attention on a particular linguistic aspect. For example, one of the words whose historical aspect was examined amazed students with the clarity of its meaning and spelling protivnik [opponent] - protiv [against]), another is amazed by a story (ruble is from rubit' [to chop]), and a third is amazed by the connections (lisa [fox] - lisy [which means bald, or yellowishred].

The novelty of the methodology that we have examined consists in a meta-subject approach to constructing RFL lessons, to the intensive formation of reliable skills for spelling on the basis of the etymological analysis of a word and in the development of connections between subject items. If one is to study RFL using etymological analysis during lessons, as well as in the form of separate 
elements within the range of corequisites during lessons on regional studies, sociolinguistics and other subjects, this will assist with the following:

- the enrichment of students' understanding of RFL on the level of a deeper mastery of the lexical and grammatical structure of language and having a positive impact on the quality of linguistic preparation and the level of education;

- in perfecting the organization of inter-subject connections through the comparative-historical method for the study of RFL;

- impacting the quality of the development of intellectual interest in studying RFL.

A teacher who has etymological analysis skills can give students appropriate historical commentaries on the words being studied. This allows the teacher to systematically improve the spelling abilities of students. There is another plus when using etymology during lessons of Russian as a foreign language: this work substantially increases student interest in the subject being studied. Surveys showed that the interest of students (second and third year) for RFL increased from $40 \%$ to $90 \%$. And this is logical due to the fact that etymology provides information on a whole range of amazing facts about words that at first seem to be commonplace. By regularly and systematically informing students of these facts, we can make RFL lessons no less interesting than history or literature lessons. In addition to an amazing story we receive simplified spelling as an extra: the possibility of checking unstressed vowels in words. When we explain the initial morpheme components of words with the assistance of etymology, then at the same time we achieve another result: a word with an abstract, lexical meaning that is difficult for a foreigner to understand due to its correlation with understandable words (komponovat [make from components] - means to compose, okolny [from the word okolo - "around, near"] - this is neighboring, i.e. indirect) comes to be perceived more specifically, with awareness, and this makes it easier to master it. This method also makes it possible to examine word formation nests of the Russian language in detail, to ease mastery and memorization of new vocabulary words, and to expand student vocabulary.

Linguistic experiments were conducted on the groups of students of the Institute for International Education and Language Communication at the National Scientific Research Tomsk Polytechnic Institute. 50 students took part in the experiment.

The data which confirmed the experiment visibly demonstrated students' level of knowledge in the field of etymology and also the level of formation of their ability to analyze RFL vocabulary and also made it possible to come to a conclusion regarding the necessity of deepening students' knowledge in the field of etymological analysis.

These exercises have the goal of developing an ability to analyze vocabulary from an etymological standpoint taking into account the specifics of the linguistic consciousness of bilingual students.

For example, the students analyzed the following lexical pairs:

Cherep - cherepakha - cherepitsa [skull, turtle, roofing tile]; dat' - dar [to give, gift].

An etymological dictionary provides information that a turtle received its name from its shell, which is hard, like a skull. The initial word cherep [skull] meant "clay splinter, cherepok [pottery fragment]." The meaning of the " bony structure in the head " appeared later and was clearly ironic. The word CHEREPITSA is also in this etymological nest ("roofing material," which was initially made from clay, which reminds one of the skull and its form).

Dar [gift] is something that I daryu [I give] (dano [is given]).

Performing this exercise may contribute to improving students' understanding of the particular character of the linguistic consciousness. This exercise makes it possible to expand and activate student vocabulary and develop a feeling for the language.

The results of experiment are presented in Fig. 2. One can see the activation of student vocabulary during the experiment. At the beginning both groups had the same level of analytical 
abilities for interpreting words using the etymological analysis. After a number of the exercises with the application of etymological commentary, a positive trend to interpret etymological concepts was noted in the experimental group: $90 \%$ students have successfully done the exercises.

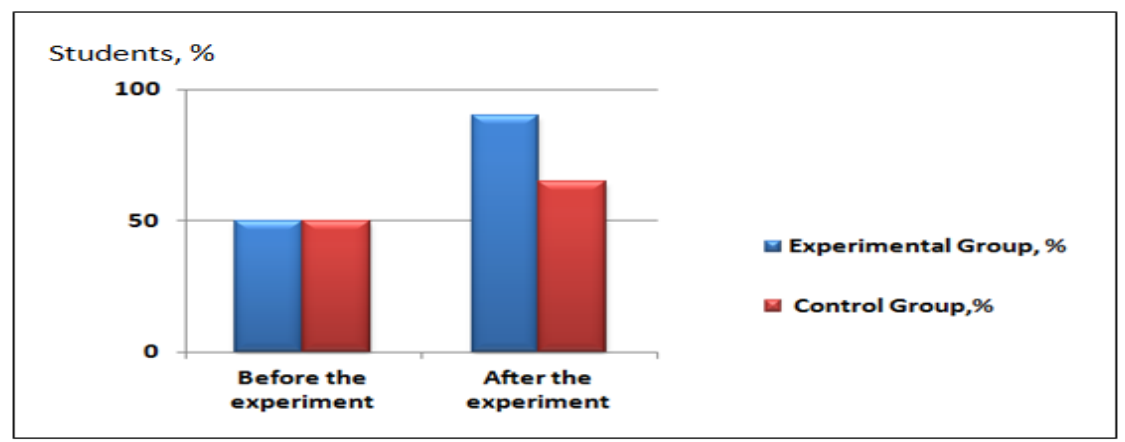

Figure 2. The Development Trend of Etymological Concepts Interpretation Ability

During the teaching experiment, practical lessons were done using an external program for the purpose of deepening and broadening students' theoretical base in the area of etymology in order to establish abilities to analyze and comment upon vocabulary taking into account etymological analysis. Versions of exercises were developed that focused on groups of students who differed in their level of preparation on various grammatical topics and on various mnemonic techniques for acquiring information. For example:

1) Separate out the internal form of words: burelom, gorbushka, metel, oranzheria, pyatnitsa [windfall, rump, snowstorm, greenhouse, Friday]. Performing the task requires selecting words on the basis of their adjacency (semantic proximity) and related words burelom - burya, lomat', veter, uragan [windbreak, storm, break, wind, storm], etc. To complete the assignment, it is advisable to use a dictionary or etymological resources on the Internet: bu-re-lom [windfall]. 1. collective. wood which has been broken or struck down by a storm. 2. a section of forest which is filled up with such trees. 3. metaphorical, poetic, disorder, mess. In this way, the bilingual students discover the direct metaphorical meaning of words. The size of the lesson is calculated using the time spent to complete the entire lesson. The novelty of the knowledge received, as knowledge that is confirmed by searching the dictionary, is perceived with praise: I did it!

2) Define for yourself (if it is difficult, then use a dictionary) why these objects are called this in the Russian language:

zveri [animals: kosulya [roe deer], lyagushka frog (from the verb lyagat' [kick]), ovcahrka [sheep dog], pesets [arctic fox] (from pes [dog] + the suffix -ets);

birds: indyuk [turkey] (from India), kanareika [canary] (from the Canary Islands), petukh [rooster] (pet' [sing]), sinitsa [chickadee];

plants: gvozdika [carnation], lebeda [orache herb] (from the word lebed' - [swan] - white (internal side of a sheet)), oduvanchik [dandelion]. Sometimes when performing the tasks, one must encounter word formation improvisations: indyuk, inyuika, indeika, indiika, indyushka [diminutive forms of the word for a "turkey"]; kanareika, kanareets, kanarets [diminutive forms of the word for "canary"]. One must be ready to discuss problems of false etymology and paronymy. Sometimes it is difficult to explain a choice of one or another suffix in a word convincingly from a grammatical standpoint, therefore, for the first examples, one should try to avoid such problems, and then after sufficient morphological knowledge has been accumulated, more complex examples can be offered.

3) Try to find a historical root in the words, and then use it to explain the source meaning of the words, as well as to separate out the suffix: borovik [boletus mushroom], lisichka [chanterelle mushroom], maslyonok [yellow boletus mushroom], opyonok [honey fungus], podberyozovik [birch 
boletus mushroom], syroezhka [russula mushroom]. Turning to the history of the language in work with foreign students always carries a certain risk because it presumes not only a high level of abstraction when performing a task, the identical character of natural and historical realities, but it must also take into account the particularities of the entire grammatical system of the native language and the Russian language (in Nigeria mushrooms not only have different names, they also look differently). It must be objectively possible to complete an assignment.

4) Using an etymological dictionary, determine the common component in the words kompot, kompozitor, compozitisia, componovat [compote, composer, composition, put together]. At the same time, one can check for word division skills, play with words and with the dictionary as guessing games. It is good if the word "mix" is pronounced in the answers. It is a difficult assignment, but an intriguing improvisation. One can find words with these components on the Internet. Let's look at an example such as shchepka, shchepetilnyi, otschepenets, chepukha [chip, scrupulous, outcast, nonsense] - general lexical meaning of - thin, fine, chipped off of (from a tree or a group of people). In this example, it is necessary to pay attention to the historical change in the lexical meaning of the word "shchepetilny" [scrupulous] in Pushkin's novel "Evgeny Onegin":

"Everything to sate boundless caprice

Is traded by London shchepetilny...»

In this context, the word shchepetilny has the additional antiquated meaning of "related to trading in haberdashery - small personal goods."

5) Is it possible to say: old veteran, life biography, one's own autograph, an herb garden of plants. This is a topical assignment that requires knowledge of the fundamentals of Russian speech culture. Speech mistakes in living speech have become very widespread, for example: preiskurant [pricelist], a, m. [from the German Preis - price and the French courant - current], and in widespread texts one finds this all over the place: Preiskurant of prices of for-charge medical services provided for by Polyclinic No. 10." The extra word is not only a mistake in live speech, but also a means for its humorous stylization: there you are five rubles of money, and go live it up, don't deny yourself anything!

6) Explain what the following words have in common pomidor [tomato] and pomada [lipstick] (the etymology of these words comes from the French and Italian word combinations of pomod'oro - which literally means "golden apple." Thus, the first part of the name of this vegetable is related to the word for lipstick, which the ancient Romans made from the pulp of a certain sort of apples), krov, krovlya and sokrovishche [blood, roof and treasure] (that which is hidden - skryt - inside or which hides us from something). This exercise is directed at developing the analytical capabilities and etymological intuition of students.

7) Which words are historical relatives in each selection, and which are not. Check using an etymological dictionary.

- $\quad$ general, generalny (plan), genii [general, general (plan), genius];

- $\quad$ demonstratsia, demonstrativny, demon [demonstration, demonstrative, demon];

- $\quad k r o v$, krovlya and sokrovishche, krovavy, porkovitel, krovat [blood, roof and treasure, bloody, protector, bed].

The assignment is difficult, but significant when learning vocabulary. The student must know the algorithm for completing it. Even the best dictionaries have faults: the dictionary of M. Fasmer has imprecision and mistakes when reflecting Russian-Turkish and Russian-Finno Ugric connections, therefore in this case, navigation in solving similar problems is more significant.

A confirming experiment showed that the majority of students are able to correctly complete this assignment. The purpose for including it in an experimental teaching program is that its completion may also aid in developing a feeling for the language.

8) The following exercise has the purpose of opening up the semantics of words created on the 
basis of folk etymologies. A false, or folk etymology, may be examined as a type of folk art, which has a certain amount of wit (for example: "vintilator [vs. ventilator - fan] - from the word "vint" [screw]; "podcherk" [a person's handwriting] from the word podcherknut [underline, emphasize] et al.), and so work with words of this type very much livens up a lesson, not only activating the students' mental activity, but also stimulating the development of their linguistic intuition and their sense of humor. For instance, the French "sale" - dirty - has served as a source for the formation of the adjective salny [greasy, raunchy] (the change in meaning occurred through the similarity in sound to the word salo [lard]) or the history of the appearance in the Russian language of the word "shval" - a worthless person or unneeded thing, This lexeme was borrowed during the Napoleonic Wars in 1812; Russian soldiers (who mainly had a peasant background and did not know the French language) when hearing the word chevalier [knight] - a title with a noble origin, gave a popular negative connotation and transmitted it with the phonetic version which is known to us.

More often a false etymology arises in cases when a person wants to check the spelling of a difficult word whose origin is unknown to him/her. Bilingual students compare words, for example: "sveshchenny"[vs. correct svyashchenny, "holy"] - from the word svet [light]; "sportakiada" [vs. correct "spartakiada"] - from the word sport etc.

Sample of an exercise:

Please, show instances of false etymology in micro-texts:

Poyasnitsa [lower back from poyas - belt] - a person who explains [poyasnit].

Izvestnyak [limestone] - is a well-known [izvestny] person.

Boikot [boycott] - is a boyevoi kot [fighting cat] (boy [fight] + kot [tomcat]).

Vinograd [grape] - is a city of wine (vino [wine] + grad [town]).

In order to effectively remember the meanings and spelling of words, it is recommended to compile a dictionary with illustrations on the topics being studied. For example:

Kvartira [flat, apartment] is a word which is formed from the Latin quartarius - a quarter (a special duty, a type of tax). For this duty a soldier was put on duty and, consequently, a kvartira is a place where a soldier is posted.

Soldat [soldier] is borrowed from the German Soldat, but it comes from the Italian soldo - coin, money, pay. I.e. literally "one who receives pay."

Tramvai [streetcar] - is the English tram - wagon, way - road, way.

The effectiveness of this type of dictionary work during RFL lessons confirmed the experiment when the control group, CG, was asked to learn 10 words (dictionary words) without an etymological commentary, and the experimental group, EG, received the words with the etymological illustrations. The diagrams of spelling mistakes given below prove that the substantiated understanding of the structure leads to a reduction in spelling mistakes and that rote learning has a low percentage of learning quality. 


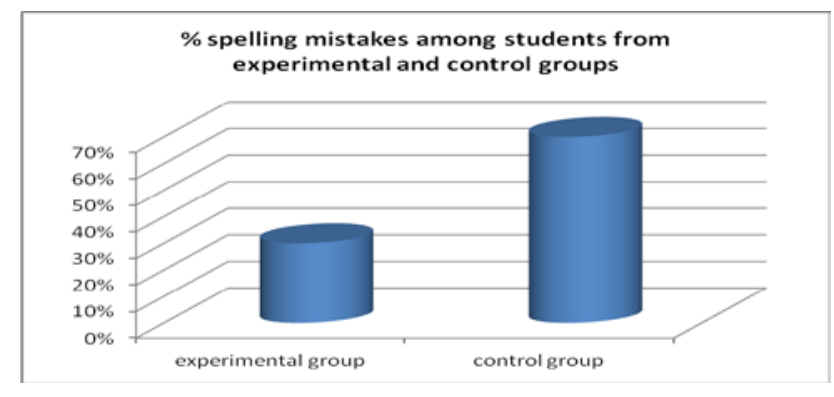

Figure 3. Comparative Diagram of Spelling Mistakes among 50 Students from both Groups:

Experimental and Control.

The basic exercises that have a high motivating effect and features of universality during RFL instruction are exercises developed on the basis of etymological analysis of words using the method of "simple analogies." This method was used at the start of RFL instruction and at the end of the course of instruction (during the 2014-2018 academic years). The classic method was adapted to the conditions for teaching bilingual students.

At the beginning of the experiment, both groups were given a similar exercise. Goal: to discover the character of the logical connections and relations between concepts based upon the etymological analysis of the words offered. The respondent had to establish a logical connection in the provided lexemes. Observations during the course of the experiment showed that the performance of the task caused difficulties. They began to complete it in stages.

At the first stage, it was necessary to form and understand through association a series of provided words, for example:

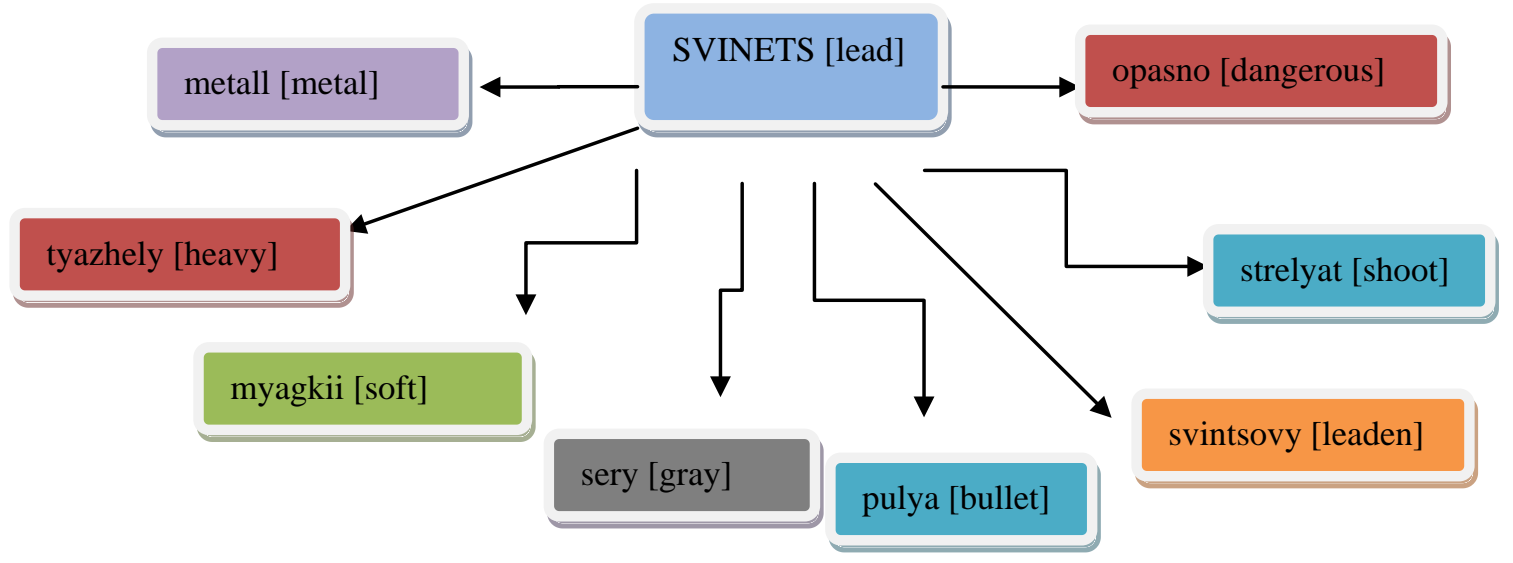

Figure 4. Associative Field of the Word "Lead"

Moreover, a group of words was activated which are proximate on the basis of personal associations and, therefore, there are grounds for them to be more easily memorized and in addition, words are discovered which belong to different parts of speech - this is an accompanying review of grammar.

The second stage is the establishment of logical connections between the words which have been offered: pukh [fluff, down]: trudny, pushisty, perina, pero, lebediny [difficult, fluffy, quill, pen, swan-like]. Here, while the correct contextual usage of words is important, it makes it possible to discover things that are not necessary. Here is the most difficult assignment: compose a sentence with the words tyazhely [heavy] and trudny [difficult] so that they sounded like synonyms in one, and not in the other. 
Table 1. Examples of Exercises on Logical Thinking

\begin{tabular}{|c|c|c|}
\hline $\begin{array}{l}\text { Item } \\
\text { No. }\end{array}$ & Associations & Logical connections \\
\hline 1 & $\begin{array}{l}\text { Svinets [lead] is } \\
\text { tyazhely [heavy]. }\end{array}$ & $\begin{array}{l}\text { Pukh [fluff, down]: trudny, pushisty, perina, pero, lebediny } \\
\text { [difficult, fluffy, quill, pen, swan-like]. }\end{array}$ \\
\hline 2 & $\begin{array}{l}\text { Palets }- \text { persten } \\
\text { [finger }- \text { finger } \\
\text { ring]. }\end{array}$ & $\begin{array}{l}\text { Ruka [arm, hand]: braslet, koltso, koleso, kolchuga, koleya } \\
\text { [bracelet, ring, wheel, chain mail, wheel rut]. }\end{array}$ \\
\hline 3 & $\begin{array}{l}\text { Noga [leg] - kostyl' } \\
\text { [crutch]. }\end{array}$ & $\begin{array}{l}\text { Glaza [eyes]: ochki, zreniye, zrit', prozret', ochi [glasses, vision, } \\
\text { see, perceive, eyes]. }\end{array}$ \\
\hline
\end{tabular}

A control experiment was conducted at the end of a year of lessons using this methodology. The results are reflected in the Figure 5.

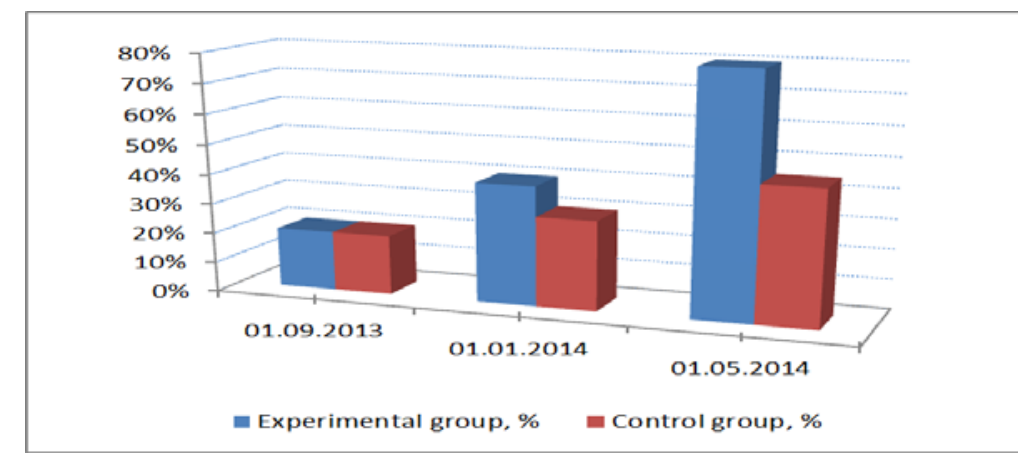

Figure 5. The Quality Percentage of the Learning Using Etymological Analysis in the Experimental Group and the Control Group.

The advantages of using etymological information during RFL lessons are evident. This method makes it possible to convert many unchecked spellings into those which are easily checkable and connects words, which were previously unconnected in the consciousness of foreign students, into convenient memorization groups with clear semantic and word formation connections between the elements. Moreover, this work has the same impact at all stages of RFL learning. Besides which, the etymology stimulates the development of interest towards the Russian language, it forms a sharp eye for spelling (the ability to see a constructed series of morphemes, and not just a series of letters in a word) and linguistic erudition.

The control experiment made it possible to establish an expansion of the main etymological concepts to form higher-level abilities to comment upon vocabulary from an etymological viewpoint and for explaining the meanings of words in the Experimental Group in comparison to the results in the Control Group. 
Table 2. The Etymological Notions (Comments)

\begin{tabular}{|c|c|c|c|c|c|c|c|c|}
\hline \multirow[t]{3}{*}{ List of concepts } & \multicolumn{4}{|c|}{$\begin{array}{l}\text { Those who gave an } \\
\text { interpretation of the concept (\%) }\end{array}$} & \multirow{2}{*}{\multicolumn{2}{|c|}{$\begin{array}{c}\text { Given } \\
\text { examples } \\
(\%)\end{array}$}} & \multirow{2}{*}{\multicolumn{2}{|c|}{$\begin{array}{c}\text { Not given } \\
\text { examples } \\
(\%)\end{array}$}} \\
\hline & \multicolumn{2}{|c|}{ Correct } & \multicolumn{2}{|c|}{ incorrect } & & & & \\
\hline & $\overline{\mathrm{EG}}$ & $\overline{\mathrm{CG}}$ & EG & CG & EG & CG & $E G$ & $\overline{C G}$ \\
\hline Etymological nest & 85 & - & 15 & - & 70 & - & 30 & - \\
\hline Popular (false) etymology & 85 & 20 & 15 & 80 & 90 & 30 & 10 & 70 \\
\hline
\end{tabular}

The reliance upon material that is topical for the student makes it possible to vary the formalthematic content of the course and only the depth of the variation analysis focused on success remains unchanged. Social anxiety is overcome and gestures and pauses become instrumentally expressive. The choice of the corresponding exercises becomes a very important moment. Each of them must contain an element of novelty and eccentricity for the student. Before proposing [for the student] to make a report, it is possible to offer wordplay.

\subsection{Independent Student Work}

Independent student work in the subject matter is considered to be a mandatory pedagogical phenomenon in higher education, which has its own history and which changes regularly. The growing intellectual background and emotional relationship to the subject matter of bilingual students who regularly participate in work outside of class creates favorable conditions for increasing the quality of knowledge and actively perceiving the content of the subject matter being studied and this requires constant enrichment from the teacher and a renewal of the teacher's own arsenal of methods and teaching tools. Independent joint work out of class has an impact not only on the development of students, but also on the professional development of the teacher, it becomes an integral part of the teacher's professional activity.

Independent student work is built upon the basis of the "triad of speech culture: normative, communicative and ethical aspects which are realized rationally, emotionally and through flow. When this occurs, there is a breakthrough in the comprehensive development of the person - the success makes the student feel that they now have wings! R. Bart felt this very acutely at the end of the last century: "... between science and letters... there is an area of satisfaction" [15].

Participation in long-distance academic competitions is aimed at in-depth study of individual topics on the Russian language, the development of the written speech, and the creative abilities of students. Preparation for a competition requires studying additional material on a selected topic and the striving towards victory motivates the student towards more intense study, the reading of additional literature, study of video materials and information on the Internet. Second and third year students (who are studying RFL) who came from China, Vietnam, Mongolia and Turkey took part in the Russian language competitions conducted by the N.P. Ogareva National Research Mordovia State University, in the Vth International Russian Foreign Language Contest for the 2014/2015 academic year (City of Yekaterinburg). Proof of the effectiveness of this type of motivation activity is the presence of 17 third-year students who took first and second place at the international academic competition during the 2014-2015 academic year.

The group of third-year students took an interactive remote course for learning RFL on the topic: "Sketches of Siberia. The City of Tomsk." The topic of the course offers the development of linguistic, linguistic-country knowledge and cultural expertise competencies. If students successfully complete this course, they are given a certificate, which created a venue for success 
and motivated them for further in-depth study of the subject matter. Success is an important stimulus for the positive relationship of students towards the activity. If the student is not motivated to succeed in the work, the flame of the thirst for knowledge will be extinguished... "Success in learning is a source of internal strength which gives birth to the energy to overcome difficulties, the desire to study" this is how V. Sukhomlinsky, one of the classics of Russian national pedagogical science, put it.

Success in the classroom and extracurricular activity is an effective way for students to affirm themselves. When success comes, external stimuli such as cheering on and praise become secondary and an internal satisfaction from success moves into a primary position. Success in classroom work as well as in extracurricular work acts as an important stimulus for a positive relationship with these types of activities, and a means for strengthening it. The use of comedy competitions during RFL lessons is a series of engaging assignments, riddles presented in various topics, requires intensive preparation and a great approach in order to perform the unit of assignments. Comedy competitions make it possible to use meta-subject approaches which motivate students to prepare for the game independently and with self-awareness, obtaining deeper knowledge on the topic. The students held comedy competitions on the following topics: "Lomonosov. Biography. Scholarly Activity," "New Year. Traditions of Various Countries" et al.

One of the development trends in higher education is the transition from traditional humanitarian educational technologies to developing ones. One of the active educational technologies is project learning, that goal is to create the conditions when students:

1. independently and willingly acquire knowledge that is lacking from various sources;

2. learn to use the knowledge required to solve educational and practical tasks;

3. acquire communication skills by working in various groups;

4. develop research skills.

A modern educational project is a didactic means for activating independent educational and creative activity and for the formation of the personal qualities of the student. The use of the project method during classroom and extracurricular activity makes it possible for bilingual students to form an objective system of understanding regarding their knowledge, their capabilities and their ability to realize them. A project motivates the students to show intellectual abilities, moral and communication qualities, to demonstrate the level of possession of knowledge and general educational skills, goal-setting as well as the capability for self-education and self-organization. The joint activity realistically demonstrates the broad capabilities for cooperation, during the course of which students set goals, determine the optimal methods for achieving them and comprehensively check their level of competence. Project activity clearly demonstrates the possibility of mono-and poly-subject, individual and group projects. Study with use of project methods at RFL lessons and independent student work has a whole series of advantages, because work on projects aids with the following:

1) increasing the significance of language as a way to interact;

2) developing the ability to work as a team;

3) increasing student motivation;

4) the integration of all types of speech activity.

The project method makes it possible to form personal qualities that are developed only in the individual's own activity during the process of team, group activity. First of all, one can emphasize such qualities as the ability to work on a team, to take responsibility for choice, to divide up responsibility and to feel like a member of a team. Foreign students not only study and analyze information, but work together on some sort of project: a topic is chosen, study methods are developed, a presentation is developed utilizing the obtained results. 
One example is a creative project in the form of a role-play organized in the form of a mock trial on "Love: Happiness or Tragedy for Humanity?" During this project students were able to demonstrate their erudition in the most varied fields: from the topic of courtroom proceedings to classical literature and the film business. As a result, students held a mock trial (based upon the television projects of Russian television), they conducted serious repertory analytical work for studying literature, expanded their vocabulary, practiced their performance before a large audience and learned how to work as a team.

The results of the study correlate to the methodological ideas of teaching a foreign language under conditions of bilingualism and they show that they have a universal character: during the learning process, students consciously begin to use a "second window to the world," the methodology for learning RFL that relies upon the data of etymological resources aids in expanding the cognitive space of bilinguals, it forms and corrects the individual linguistic-cultural code, and impacts the emotional and motivational level for the communicative activity of a bilingual in a multicultural format.

Additionally, etymological knowledge expands knowledge of language as a system, it corrects communicative behavior taking into account the traditions of another linguistic social environment, it establishes the foundation for developing an image structure of the foreign language and develops meta-linguistic intuition, increasing the level of the professional competency of the students.

Studying Russian language as a foreign language taking into account exercises using etymological analysis is entirely effective in a common Indo-European language space, which is characterized by a multiplicity of borrowings, common roots in words and even in turns of phrase. The grammatical similarity and recognizability of several words during writing and pronunciation become a reliable support in the formation of a picture of the world of neighboring languages, therefore, when studying languages which are in close contact, one should include not only elements of etymological analysis in the lesson plan, but also basic cultural components: parables, national phraseology and ethno-cultural characteristics of ways of life and traditions.

The study of languages of closed and weakly contacting cultures is more difficult, for example Chinese, Mongolian, Vietnamese etc. There are few borrowings into Russian from these languages; therefore, the principle of an etymological approach to increasing the motivation to learn Russian language does not find reliable support. In this situation, the cognitive space of bilinguals is actively expanded on the basis of a comparative and counter-positional study of phraseology, which evokes interest in the cultures being studied. The formation of linguistic competency aids in "recognizing" internal forms of words during the process of the etymological analysis of lexical units, the restoration of source, primary meanings that are formed at the moment of nomination.

Mutual understanding of those who are communicating in a live interaction always takes precedence over the linguistic correctness with which speech is formed. Exercises built upon wordplay have a high motivational effect and exercises that focus on precision of observation in the form of a joke also teach one to command the stylistic varieties of the language. Moreover, experience in the etymological analysis of words may be required as well as experience in translating syntactical constructions, both those with equivalents and those without equivalents that have been acquired during the translation of phraseology and idioms in the language being studied.

The use of etymological analysis in combination with lingual-cultural methods of teaching, the application of digital educational technologies, project and study-research work increase the motivational trend in teaching bilinguals at the advanced level of the study of a foreign language. 


\section{Conclusion}

In order to form a full-fledged motivation for learning activity, it is necessary to develop staged, specially organized work. The learning and informational motivations of the student community related to the internal content and process of study are created during the course of the active development of learning activity and not outside of it. The use of etymological analysis, digital educational resources (DER), the organization of independent student work and project activity developed communicative skills, creativity and curiosity, critical and systematic thinking, the ability to work with information and media tools, interpersonal interaction and cooperation as well as promoting the desire to participate in various academic competitions, projects and scientific conferences. In solving new methodological tasks and deepening knowledge of the subject matter, the teacher increases their professional level, increases their authority among students and colleagues and stimulates the process of joint creativity with educators in adjacent disciplines. The experimental methodology provided for studying vocabulary on the basis of etymological analysis, DERs and independent student work for the purpose of expanding student vocabulary, improving a feeling for the language and the research abilities of those who are learning turns out to be effective, as confirmed by the results of the quantitative and qualitative analysis of the results of the final cross-section conducted after the experimental teaching.

The results of the confirming, learning and the controlled experiments testify to the effectiveness of the usage of this methodology as a means for optimizing teaching RFL vocabulary to bilingual students, which is expressed in increasing the level of knowledge of the students not only in the field of etymological knowledge, but also the expansion of their vocabulary (through a nested presentation of the material), in expanding their linguistic horizon, and increasing the level of professional competency in the formation of an integrated idea of the lexical system of RFL among bilingual students.

This system of work was tested for three years and its effectiveness was confirmed. Diagnostics were carried out on the basis of long-term monitoring, student surveys, interviews, pedagogical observation as well as testing and written work of students. A positive trend was discovered in the cognitive and affective aspects of the development of the confidence of foreign students. The motivation and inquisitive activity of foreign students increased, the level of the development of thought processes and the mastery of creative techniques was increased. The positive development trend for creative confidence is reflected in the student portfolios. The creative growth is testified by the increased number of participants and winners of federal competitions, international scholarly conferences and academic competitions.

\section{References}

[1] Abdur Rehman, Hafiz Ahmad Bilal, Ayesha Sheikh, Nadia Bibi, \& Asma Nawaz. (2014) The Role of Motivation in Learning English Language for Pakistani Learners. International Journal of Humanities and Social Science, 4, 1, 254-258.

[2] Aksenova, N. V, \& Shepetovskii D. V. (2014) Using an electronic resource of Wikipedia in teaching reading comprehension at the primary stage in the technical University . Molodoi ucheny (Young scientist) 1 (60), 465-468 [in Russian]

[3] Chubik, M.; Slesarenko, I. (2012) Educating Competitive Engineers as a Response to New Industrialisation Environment. ICERI2012 Conference, pp. 6265-6271 
[4] Dörnyei, Z. (1998). Motivation in second and foreign language learning. Language Teaching, 31, $117-135$.

[5] Dörnyei Z., \& Ushioda E. (2013) Teaching and Researching: Motivation. Applied Linguistics in Action. Second Edition. New York: Routledge.

[6] Jaclyn Bernard. (2010) Motivation in Foreign Language Learning: The Relationship between Classroom Activities, Motivation, and Outcomes in a University. Language-Learning Environment. Dietrich College of Humanities and Social Sciences. Carnegie Mellon University.

[7] Kassim A. Shaaban, Ghazi Ghaith. (2000) Student Motivation to Learn English as a Foreign Language / Foreign Language Annals, 632-644.

[8] Leonyev A. (1983). Selected Psychological Works. Moscow: Pedagogy.[in Russian]

[9] Li, P. \& Pan, G. (2009) The relationship between motivation and achievement: A survey of the study motivation of English majors in Qingdao Agricultural university. English Language Teaching, 2(1), 123-128.

[10] Masanori Matsumoto (2009) Second language learners' motivation and their perceptions of teachers' motivation. Humanities \& Social Sciences papers. Bond University.

[11] Mormugoeva, N. V. (2013) Motivation of student learning in professional institutions. Pedagogy: traditions and innovations: proceedings of the IV Intern. scientific. Conf. (Chelyabinsk, December 2013).

[12] Mostafa Papi and Yasser Teimouri Language Learner Motivational Types: A Cluster Analysis Study. Language Learning, 64, 3, 493-525

[13] Naghmeh Babaee. (2012) Motivation in Learning English as a Second Language: A Literature Review. Canadian Journal for New Scholars in Education. 4, 1, 1-7

[14] Savilova S. (2013) Increasing the Motivation of Students to Study Languages Using the Etymological Analysis of Words with the Application of Informational and Communicational Competency. Proceedings of the Scientific conference "Level-based Training specialist: State and International Standards for Engineering Education”, 250-254

[15] Shchitov A. (2012) Methodological Particularities of the Formation of General Cultural and Professional Competencies in Teaching the Russian Language and Speech Culture at a Technical Institution of Higher Learning. Young Philology of Siberia, 85-94. [in Russian]

[16] Slesarenko I. V (2012) Professional Training - English as Foreign Language Enhancement Courses for Content Teachers at Technical University. Proceedings of 4th International Conference on Education and New Learning, Barcelona, Spain. pp. 5566-5570

[17] Thanasoulas D. (2002) Motivation and Motivating in the Foreign Language Classroom. The Internet TESL Journal, VIII, 11.

[18] Tinghe Jin. (2012). Getting to know you: The development of intercultural competence as an essential element in learning Mandarin. London Review of Education, 12, 1, 20-33.

[19] Xiaohong Wen. (1997) Motivation and Language Learning with Students of Chinese. Foreign Language Annals, 30, 2, 235-251 